\title{
Use of Confocal Microscopy to Evaluate Equine Zygote Development After Sperm Injection of Oocytes Matured In Vivo or In Vitro
}

\author{
Elena Ruggeri, ${ }^{1,2}$ Keith F. DeLuca, ${ }^{3}$ Cesare Galli, ${ }^{4,5}$ Giovanna Lazzari, ${ }^{4,5}$ Jennifer G. DeLuca, ${ }^{3}$ \\ Joanne E. Stokes, ${ }^{1}$ and Elaine M. Carnevale ${ }^{1, *}$ \\ ${ }^{1}$ Department of Biomedical Sciences, Colorado State University, 1693 Campus Delivery, Fort Collins, CO 80523, USA \\ ${ }^{2}$ Department of Obstetrics/Gynecology Reproductive Sciences, University of California, San Francisco, 513 Parnassus Avenue, \\ San Francisco, CA 94143, USA \\ ${ }^{3}$ Department of Biochemistry and Molecular Biology, Colorado State University, 1870 Campus Delivery, Fort Collins, CO 80523, USA \\ ${ }^{4}$ Laboratory of Reproductive Technologies, Avantea, Via Porcellasco 7f, 26100, Cremona, Italy \\ ${ }^{5}$ Fondazione Avantea, Via Porcellasco 7f, 26100, Cremona, Italy
}

\begin{abstract}
Confocal microscopy was used to image stages of equine zygote development, at timed intervals, after intracytoplasmic sperm injection (ICSI) of oocytes that were matured in vivo or in vitro. After fixation for 4, 6, 8, 12 , or $16 \mathrm{~h}$ after ICSI, zygotes were incubated with $\alpha / \beta$ tubulin antibodies and human anticentromere antibody (CREST/ACA), washed, incubated in secondary antibodies, conjugated to either Alexa 488 or Alexa 647, and incubated with 561-Phalloidin and Hoechst 33258. An Olympus IX81 spinning disk confocal microscope was used for imaging. Data were analyzed using $\chi^{2}$ and Fisher's exact tests. Minor differences in developmental phases were observed for oocytes matured in vivo or in vitro. Oocytes formed pronuclei earlier when matured in vivo $(67 \%$ at $6 \mathrm{~h}$ and $80 \%$ at $8 \mathrm{~h}$ ) than in vitro (13\% at 6 and $8 \mathrm{~h}) ; 80 \%$ of oocytes matured in vitro formed pronuclei by $12 \mathrm{~h}$. More $(p=0.04)$ zygotes had atypical phenotypes, indicative of a failure of normal zygote development, when oocyte maturation occurred in vitro versus in vivo (30 and 11\%, respectively). Some potential zygotes from oocytes matured in vivo had normal phenotypes, although development appeared to be delayed or arrested. Confocal microscopy provided a feasible method to assess equine zygote development using limited samples.
\end{abstract}

Key words: zygote, confocal microscopy, equine, ICSI, cytoskeleton

\section{INTRODUCTION}

Conventional in vitro fertilization has had poor success for horses (Squires et al., 2003; Leemans et al., 2016). However, assisted fertilization using intracytoplasmic sperm injection (ICSI) resulted in experimental pregnancies and limited offspring by the mid-1990s (Squires et al., 2003; Galli et al., 2007). Subsequently, ICSI was developed for clinical use in horses, with the production of pregnancies and offspring from subfertile mares and/or stallions with limited or poor sperm quality (Carnevale et al., 2007; Colleoni et al., 2007; Hinrichs, 2013). As the demand for ICSI increased in the equine industry, methods for maturing oocytes and culturing embryos in vitro were explored (Carnevale \& Sessions, 2012; Hinrichs, 2013; Galli et al., 2014). However, our understanding of equine fertilization and early embryo development is still limited.

Oocytes can be matured in vivo or in vitro for equine assisted reproduction. Oocyte maturation is induced in vivo by administration of compound(s) to the donor mare that initiate follicle and oocyte maturation within the dominant follicle during the follicular phase, and the oocyte can be

Received September 7, 2017; accepted November 4, 2017

${ }^{*}$ Corresponding author. Elaine.Carnevale@colostate.edu collected from the follicle before ovulation (Carnevale, 2016). Theoretically, the resulting oocytes should be of optimal quality, and collection, oviductal transfer, and fertilization in vivo of similar oocytes result in high pregnancy rates (Carnevale \& Ginther, 1995). In vitro maturation of oocytes has been widely used in domestic animals and is of interest in human reproduction (Edwards, 1965; Hinrichs et al., 1993; Arlotto et al., 1996; Galli et al., 2007; Lonergan \& Fair, 2016). In the horse, immature oocytes are collected from live mares or excised ovaries by collecting oocytes from numerous follicles of various sizes for in vitro maturation, fertilization, and foal production (Galli et al., 2013; Hinrichs, 2013; Carnevale, 2016). The extent to which the artificial environment, associated with in vitro maturation, affects the oocyte has not been fully determined. In addition, immature oocytes from small follicles are removed from their natural environment prior the development of conditions associated with follicle growth and hormonal stimulation. Consequently, oocytes from immature follicles are more variable in quality and developmental competency (Hinrichs, 1991; Hyttel et al., 1997).

An understanding of differences in zygotes developing from oocytes matured in vivo (IVO) and in vitro (IVM) would further our knowledge of the normal progression of postfertilization events and of potential alterations in cytoskeletal and nuclear maturation prior to the first mitotic 
division. In our study, we used confocal microscopy to examine equine zygote development at timed intervals after ICSI of IVO or IVM.

\section{Materials and Methods}

\section{Oocyte Collections}

IVO were collected between April and August in Fort Collins, CO, USA ( $40^{\circ}$ latitude) from light-horse mares between 4 and 16 years (mean \pm SEM of $10.8 \pm 0.7$ year). Reproductive tracts were imaged using ultrasonography to evaluate follicular growth. Oocytes were collected from the dominant follicle(s) during the follicular phase and between 18 and $25 \mathrm{~h}(21 \pm 0.3 \mathrm{~h})$ after administration of human chorionic gonadotropin (1,500 IU, iv; Intervet Inc., Millsboro, DE, USA) and deslorelin acetate (SucroMate ${ }^{\mathrm{TM}}, 0.75 \mathrm{mg}$, im; Bioniche Life Sciences Inc., Belleville, Ontario, Canada). Oocytes were collected by ultrasound-guided, transvaginal follicle aspirations as previously described (Carnevale et al., 2000), but using a commercial embryo flush solution (ViGRO $^{\text {TM }}$ Complete Flush, Bioniche Animal Health USA, Inc., Pullman, WA, USA) to lavage the follicle. Upon collection, the oocytes were cultured for $19.5-27.0 \mathrm{~h}(22.0 \pm 0.3 \mathrm{~h})$ in Tissue Culture Medium 199 with Earle's salts (Gibco, Life Technologies, Grand Island, NY, USA) with additions of $10 \%$ fetal calf serum (FCS, Cell Generation LLC, Fort Collins, CO, USA), $0.2 \mathrm{mM}$ sodium pyruvate, and $25 \mu \mathrm{g} / \mathrm{mL}$ gentamicin sulfate (Sigma Aldrich, St. Louis, MO, USA) at 38 or $38.5^{\circ} \mathrm{C}$ in a humidified atmosphere of $6 \% \mathrm{CO}_{2}$ and air.

IVM were collected from excised ovaries in Cremona, Italy $\left(45^{\circ}\right.$ latitude) during the natural breeding season. Ovaries were obtained from mares of diverse breeds and unknown ages from a local abattoir and transported at $24^{\circ} \mathrm{C}$ for $<4 \mathrm{~h}$ before collection of oocytes at the laboratory. Retrieved oocytes were placed in culture medium [Dulbecco's modified Eagle's medium (DMEM)/F12 (D8900; Sigma Aldrich, Milan, Italy) with 10\% serum replacement (Life Technologies, Monza, Italy) and $0.1 \mathrm{IU} /$ $\mathrm{mL}$ of human menopausal gonadotropin (Menopur 75, Ferring, Milan, Italy)] for $28 \mathrm{~h}$ at $38.5^{\circ} \mathrm{C}$ in humidified atmosphere of $5 \% \mathrm{CO}_{2}$ and air.

\section{ICSI and Zygote Culture}

Prior to ICSI of IVO or IVM, cumulus cells were removed and extrusion of the first polar body was confirmed. For both labs, ICSI was performed using a piezo drill. Frozen-thawed semen from one stallion in each laboratory was used for all sperm injections, and a motile sperm with normal morphology was selected for each injection. After ICSI, potential zygotes were cultured under standard conditions for each laboratory. For IVO, potential zygotes were cultured individually in $30-\mu \mathrm{L}$ drops of medium [DMEM/F12 (Sigma Aldrich, St. Louis) with $10 \%$ FCS] under mineral oil at $38.5^{\circ} \mathrm{C}$ and in an atmosphere of $5 \% \mathrm{CO}_{2}, 5 \% \mathrm{O}_{2}$, and $90 \% \mathrm{~N}_{2}$. Potential zygotes from IVM were placed as a group into $300 \mu \mathrm{L}$ of a modified synthetic oviductal fluid medium with bovine serum albumin (BSA; Sigma Aldrich, Milan) and modified Eagle Medium amino acids (Sigma Aldrich, Milan) in four-well dishes at $38.5^{\circ} \mathrm{C}$ and in $5 \% \mathrm{CO}_{2}, 5 \% \mathrm{O}_{2}$, and $90 \% \mathrm{~N}_{2}$ (Lazzari et al., 2002; Colleoni et al., 2011).

\section{Samples Fixation and Immunostaining}

Presumptive zygotes were fixed at room temperature in a microtubule stabilizing buffer (MTSB-XF, $0.1 \mathrm{M}$ Pipes, $5 \mathrm{mM} \mathrm{MgCl} 2.6 \mathrm{H}_{2} \mathrm{O}, 2.5 \mathrm{mM}$ EGTA at $\mathrm{pH}$ 6.9) containing $2 \%$ formaldehyde, $1 \mu \mathrm{M}$ taxol, 10 units $/ \mathrm{mL}$ aprotinin, $50 \%$ deuterium oxide and modified with $0.1 \%$ Triton X-100, and $1 \mathrm{mM}$ 1,4-Dithiothreitol (Messinger \& Albertini, 1991). Zygotes were fixed at $4(n=5), 6(n=6), 8(n=5), 12(n=5)$, and $16 \mathrm{~h}(n=7)(\mathrm{ICSI}=0 \mathrm{~h})$ for IVO and at the same time points $4(n=8), 6(n=8), 8(n=8), 12(n=10)$ and $16 \mathrm{~h}$ $(n=10)$ for IVM. After fixation, oocytes were rinsed in wash solution [(phosphate buffered saline containing $0.2 \%$ powdered milk, $2 \%$ normal goat serum, $0.1 \mathrm{M}$ glycine, and modified to contain 1\% BSA and $0.1 \%$ Triton X-100 (Messinger \& Albertini, 1991)] for IVO or a modified wash solution (phosphate buffered saline containing $1 \%$ BSA and $0.1 \%$ Triton X-100) for IVM, and stored at $4^{\circ} \mathrm{C}$ until immunostaining. The same procedure for immunostaining was used for IVO and IVM.

Oocytes were incubated with diluted primary antibodies in wash solution and positioned in four-well plates on rotating platform shaker for $4 \mathrm{~h}$ at $37^{\circ} \mathrm{C}$ at the following concentrations: $\alpha / \beta$ tubulin cocktail (1:100, mouse; Sigma Aldrich, St. Louis) and human-anti centromere antibody-CREST/ACA (1:100; Life Technologies, Grand Island). After primary incubation, oocytes were rinsed in wash solution for a minimum of $12 \mathrm{~h}$ at $4^{\circ} \mathrm{C}$, then incubated with secondary antibodies conjugated to either Alexa 488 or Alexa 647 (1:100; Jackson ImmunoResearch Laboratories, West Grove, PA, USA) diluted in wash solution for $4 \mathrm{~h}$. When secondary incubation was complete, the oocytes were held in wash solution for $5 \mathrm{~h}$ and then incubated with phalloidin (Alexa 561; Life Technologies) and Hoechst 33258 ( $1 \mu \mathrm{g} / \mathrm{mL}$; Life Technologies, Grand Island, NY, USA) for another $5 \mathrm{~h}$ at $37^{\circ} \mathrm{C}$. For confocal imaging, samples were mounted onto coverslips in 50\% glycerol in phosphate buffered saline with $25 \mathrm{mg} / \mathrm{mL}$ sodium azide and $1 \mu \mathrm{g} / \mathrm{mL}$ of Hoechst 33258 (Barrett \& Albertini, 2007).

Confocal images were acquired on an Olympus IX81 microscope (Waltham, MA, USA) fitted with a Yokogawa spinning disk (CSU22 head) using either a 60X/1.42 NA, DIC Planapochromatic or a $40 \mathrm{X} / 1.35 \mathrm{NA}$ planapochromatic oil lens. Entire oocytes were imaged in $1-\mu \mathrm{m}$ intervals at $40 \times$ and $0.2-\mu \mathrm{m}$ intervals at $60 \times$. Images were captured with a Photometrics Cascade II EM CCD camera (Tucson, AZ, USA) and analyzed using SlideBook software (Intelligent Imaging Innovations, Denver, CO, USA).

\section{Determination of Zygote Development Stages and Abnormalities After ICSI}

Five sequential developmental events were categorized for presumptive equine zygotes: (1) condensed sperm chromatin 
with maternal chromosomes and extruded first polar body (PB1); (2) anaphase to telophase transition including anaphase/telophase shift of maternal chromosomes, condensed sperm chromatin, $\mathrm{PB} 1$, and second polar body (PB2) in the process of extrusion or fully extruded; (3) formation of the male pronuclei with maternal chromosomes, $\mathrm{PB} 1$ and $\mathrm{PB} 2$; (4) male and female pronuclei at distant positions; (5) male and female pronuclei in close apposition. Pronuclei (presumed male and female) were identified by localization of DNA and a human anticentromere antibody (CREST polyclonal antibody).

Development of presumptive zygotes were considered abnormal if the following images were observed: (1) premature chromosome condensation of the sperm with male chromosomes flanked by a bipolar spindle; (2) multiple pronuclei; (3) sperm chromatin induced ectopic polar body; (4) multipolar spindles with incorrect separation of chromosomes and presence of multiple centrosomes; (5) scattered maternal chromosomes and intact sperm head.

\section{Statistical Analysis}

$\chi^{2}$ Analysis was used to determine overall effects across all time points, and Fisher's exact test was used within each category for comparisons among time points if the overall difference was significant at $p<0.05$.

\section{RESULTS}

\section{Presumptive Zygote Developmental Events and Pronuclei Assessment}

A similar series of developmental events were observed during zygote development after ICSI of IVO or IVM (Fig. 1, Table 1). Because of the relatively low number of samples, differences in the number of potential zygotes at specific developmental stages were observed over time only for IVO with condensed sperm chromatin, maternal chromosomes and PB1 ( $p=0.02$, Figs. 1a-1c), IVO for presence of distant pronuclei ( $p=0.06$, Fig. $2 \mathrm{~b}$ ), and IVM for apposed pronuclei $(p=0.008$, Fig. 2a, Table 1$)$. The number of zygotes with pronuclei (distant or apposed) was significantly elevated at 12 and $16 \mathrm{~h}$ when compared with earlier time points for IVM, with the numerically highest percentage of pronuclei observed at $12 \mathrm{~h}(80 \%)$. Although not different over time, the highest numerical percentages of pronuclei were observed at $6(67 \%)$ and $8 \mathrm{~h}(80 \%)$ for IVO (Table 1$).$

At the initial observation after ICSI, many zygotes had a female spindle arrested at metaphase II with aligned and compact chromosomes, an extruded first polar body, and paternal DNA as identified by the presence of the sperm head and, in some samples, the tail (Figs. 1a, 1b). Kinetochores were associated with maternal chromosomes at the metaphase plate and in the extruded first polar body (Fig. 1c). This early phase of development was observed predominantly at $4 \mathrm{~h}$ after ICSI, including 80 and 38\% of presumptive zygotes derived from IVO and IVM, respectively. One zygote from each of the two groups had not progressed past this developmental stage at $6 \mathrm{~h}$ after ICSI, and two zygotes from each group appeared delayed or arrested in development and had not progressed from this stage by $\geq 8 \mathrm{~h}$ after ICSI.

The anaphase to telophase transition was imaged as maternal chromosomes approaching anaphase or extruding the second polar body during telophase, with the presence of a sperm head (Figs. 1d-1f). This stage was observed as early as $4 \mathrm{~h}$ after ICSI for IVO and IVM, with some presumptive zygotes arrested at this point in later hours.

Decondensation of male chromatin with a microtubule array around the sperm head nuclei, female chromosomes aligned at the metaphase plate, and PB1 with or without PB2 (Figs. 1g-1i) was only imaged in three oocytes, including IVO oocytes that appeared delayed in development at $12 \mathrm{~h}$ after ICSI.

The presence of two pronuclei, presumed male and female, were imaged as early as $6 \mathrm{~h}$ after ICSI (Fig. 2b). At $8 \mathrm{~h}$ for IVO and $12 \mathrm{~h}$ for IVM, $80 \%$ of zygotes had pronuclei. When the pronuclei were in different areas of the ooplasm (distant), they were surrounded by a complex tubulin net, which diffused throughout the developing zygote. When the two pronuclei were close, the tubulin net was concentrated and contracting at the site of apposition (Fig. 2a). The number of nucleolus precursor bodies (NPB) in both parental pronuclei varied from three to seven; NPB were imaged in all pronuclei when PB2 was not extruded and three pronuclei were present (Fig. 3b).

\section{Abnormalities Observed in Presumptive Equine Zygotes After ICSI}

Failure of zygote development was observed for IVO and IVM and was associated with abnormal cytoskeletal and chromatin configurations (Figs. 3, 4). IVO had an incidence of abnormalities during zygote development of $3 / 28$ (11\%), with no significant differences for the various phenotypes over time (Table 2). Of the 44 potential zygotes from IVM, $13(30 \%)$ had abnormal phenotypes, with the most common abnormalities being premature chromosome condensation and sperm chromatin induced ectopic polar body. Overall, potential zygotes from IVM had a higher number of abnormal phenotypes per total injected oocytes than IVO $(p=0.04$, Table 2).

\section{Discussion}

Equine zygotes are difficult to obtain, and confocal microscopy provides a potentially efficient method to analyze the limited numbers of samples. The equine oocyte is a large cell with a high lipid content (Ambruosi et al., 2009). The ooplasm measures $\sim 85 \mu \mathrm{m}$ in diameter and is surrounded by the zona pellucida, a glycoprotein layer about $12-\mu \mathrm{m}$ in thickness; the outer zona pellucida is $\sim 117 \mu \mathrm{m}$ in diameter (Altermatt et al., 2009). The size and properties of the equine oocyte affect immunostaining and confocal imaging, adding 

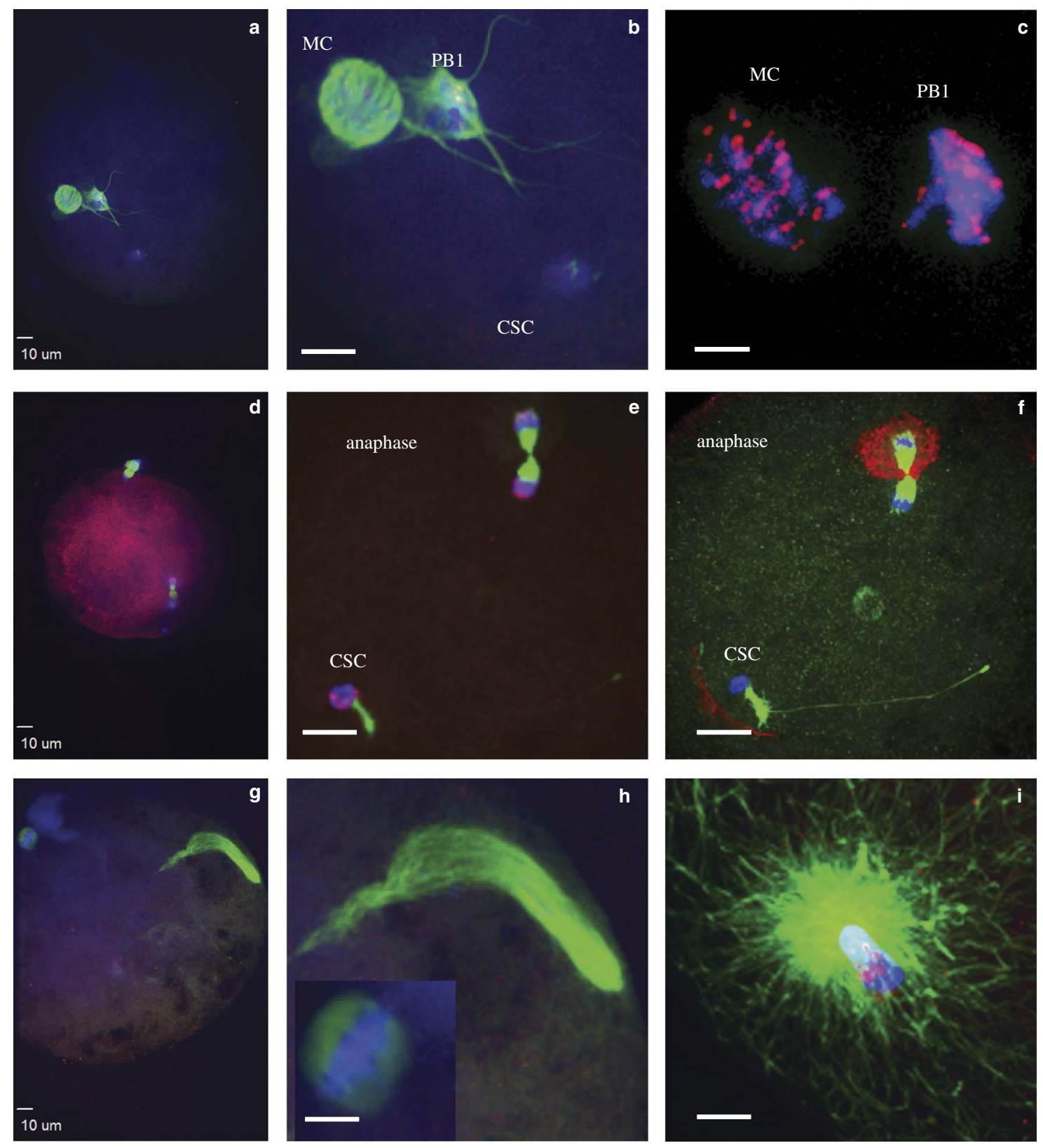

Figure 1. Events during zygote development observed between 4 and $16 \mathrm{~h}$ after intracytoplasmic sperm injection. a,b: Condensed sperm chromatin (CSC, lower right), maternal chromosomes (MC, left), and first polar body (PB1, just to right of $\mathrm{MC}$ ); (c) representation of the kinetochores localized on $\mathrm{MC}$ and $\mathrm{PB} 1 ;(\mathbf{d}, \mathbf{e})$ anaphase to telophase transition with CSC with acrosome portion of the sperm (lower left), anaphase/telophase of MC, extruding the second polar body; (f) actin cap surrounding the set of chromosomes being extruded in the second polar body, sperm tail visible next to CSC; $(\mathbf{g}, \mathbf{h})$ formation of the male pronucleus (indicated by elongated tubulin structure), MC (h, left insert); and (i) tubulin aster formation around the sperm head at the time of sperm DNA decondensation (blue, DNA; red, centromeres and kinetochores, except in panel $\mathbf{f}$ red indicates actin; green, tubulin).

difficulty to the procedures. In addition, relatively few antibodies have been tested with the equine oocyte and zygote. However, we were able to successfully incorporate antibodies that had previously been used in other species.

Historically, development of the equine zygote and early embryo has been challenging to study. The equine conceptus will remain in the oviduct for 5-6 days before entering the uterus as a morula or early blastocyst (Freeman et al., 1991). Initial observations of equine zygotes were done using transmission electron microscopy, with limited numbers of samples collected from oviducts based on timing of breeding or administration of ovulation inducing compounds (Enders et al., 1987; Grondahl \& Hyttel, 1996). Later, ICSI were used as a method to fertilize equine oocytes matured in vitro, prior to analysis by electron microscopy (Grondahl et al., 1997) or confocal microscopy (Tremoleda et al., 2003). However, at the time of these observations, procedures for equine oocyte maturation, ICSI and embryo culture were not yet easily 
Table 1. Numbers of Potential Equine Zygotes at Different Points of Development at 4, 6, 8, 12, and $16 \mathrm{~h}$ From All Oocytes Matured In Vivo (IVO) or In Vitro (IVM) And Fertilized by Intracytoplasmic Sperm Injection $(0 \mathrm{~h})$.

\begin{tabular}{|c|c|c|c|c|c|c|}
\hline Stages of Development & $4 \mathrm{~h}$ & $6 \mathrm{~h}$ & $8 \mathrm{~h}$ & $12 \mathrm{~h}$ & $16 \mathrm{~h}$ & $p$ Value \\
\hline \multicolumn{7}{|c|}{ Condensed sperm chromatin, maternal chromosomes, and first polar body } \\
\hline IVO & $4 / 5(80)^{\mathrm{a}}$ & $1 / 6(17)^{\mathrm{ab}}$ & $0 / 5(0)^{\mathrm{b}}$ & $0 / 5(0)^{\mathrm{b}}$ & $2 / 7(29)^{\mathrm{ab}}$ & 0.02 \\
\hline IVM & $3 / 8(38)$ & $1 / 8(13)$ & $1 / 8(13)$ & $1 / 10(10)$ & $0 / 10(0)$ & 0.23 \\
\hline \multicolumn{7}{|c|}{ Anaphase to telophase transition, condensed sperm chromatin, first polar body } \\
\hline IVO & $1 / 5(20)$ & $1 / 6(17)$ & $1 / 5(20)$ & $1 / 5(20)$ & $0 / 7(0)$ & 0.81 \\
\hline IVM & $2 / 8(25)$ & $2 / 8(25)$ & $1 / 8(13)$ & $0 / 10(0)$ & $0 / 10(0)$ & 0.24 \\
\hline \multicolumn{7}{|c|}{ Male pronuclei chromatin decondensation, maternal chromosomes, first and second polar bodies } \\
\hline IVO & $0 / 5(0)$ & $0 / 6(0)$ & $0 / 5(0)$ & $1 / 5(20)$ & $0 / 7(0)$ & 0.31 \\
\hline IVM & $1 / 8(13)$ & $2 / 8(25)$ & $0 / 8(0)$ & $0 / 10(0)$ & $0 / 10(0)$ & 0.16 \\
\hline \multicolumn{7}{|c|}{ Distant male and female pronuclei } \\
\hline IVO & $0 / 5(0)$ & $3 / 6(50)$ & $1 / 5(20)$ & $0 / 5(0)$ & $0 / 7(0)$ & 0.06 \\
\hline IVM & $0 / 8(0)$ & $0 / 8(0)$ & $0 / 8(0)$ & $2 / 10(20)$ & $1 / 10(10)$ & 0.32 \\
\hline \multicolumn{7}{|c|}{ Apposed male and female pronuclei } \\
\hline IVO & $0 / 5(0)$ & $1 / 6(17)$ & $3 / 5(60)$ & $2 / 5(40)$ & $3 / 7(43)$ & 0.26 \\
\hline IVM & $0 / 8(0)^{\mathrm{a}, \star}$ & $1 / 8(13)^{\mathrm{ab}}$ & $1 / 8(13)^{\mathrm{ab}}$ & $6 / 10(60)^{\mathrm{b}}$ & $6 / 10(60)^{\mathrm{b}}$ & 0.008 \\
\hline \multicolumn{7}{|c|}{ Pronuclei stages (combined distant and apposed) } \\
\hline IVO & $0 / 5(0)$ & $4 / 6(67)$ & $4 / 5(80)$ & $2 / 5(40)$ & $3 / 7(43)$ & 0.103 \\
\hline IVM & $0 / 8(0)^{\mathrm{a}}$ & $1 / 8(13)^{\mathrm{a}}$ & $1 / 8(13)^{\mathrm{a}}$ & $8 / 10(80)^{b}$ & $7 / 10(70)^{\mathrm{b}}$ & 0.001 \\
\hline
\end{tabular}

Some potential zygotes had abnormal morphologies (see Table 2) and did not fit within the developmental stages.

${ }^{*}$ One zygote from IVM had three pronuclei imaged at $4 \mathrm{~h}$ (see Table 2).

${ }^{\mathrm{a}, \mathrm{b}}$ Values within rows with different superscript letters differ with time at $p<0.05$.

repeatable or proven to produce viable embryos and foals, and timing of embryo development after ICSI was not always optimal. In the present study, proven methods were used in laboratories with records of producing viable foals after ICSI of IVO and IVM (Carnevale et al., 2007; Galli et al., 2007).
In our study, we observed zygote development at timed intervals after ICSI and noted similar events after IVO or IVM. In previous studies using ICSI and microscopic evaluations of zygotes, oocytes comparable to our IVM group were used, with oocytes collected from ovaries that were obtained from abattoirs and matured in vitro (Grondahl et al., 1997;
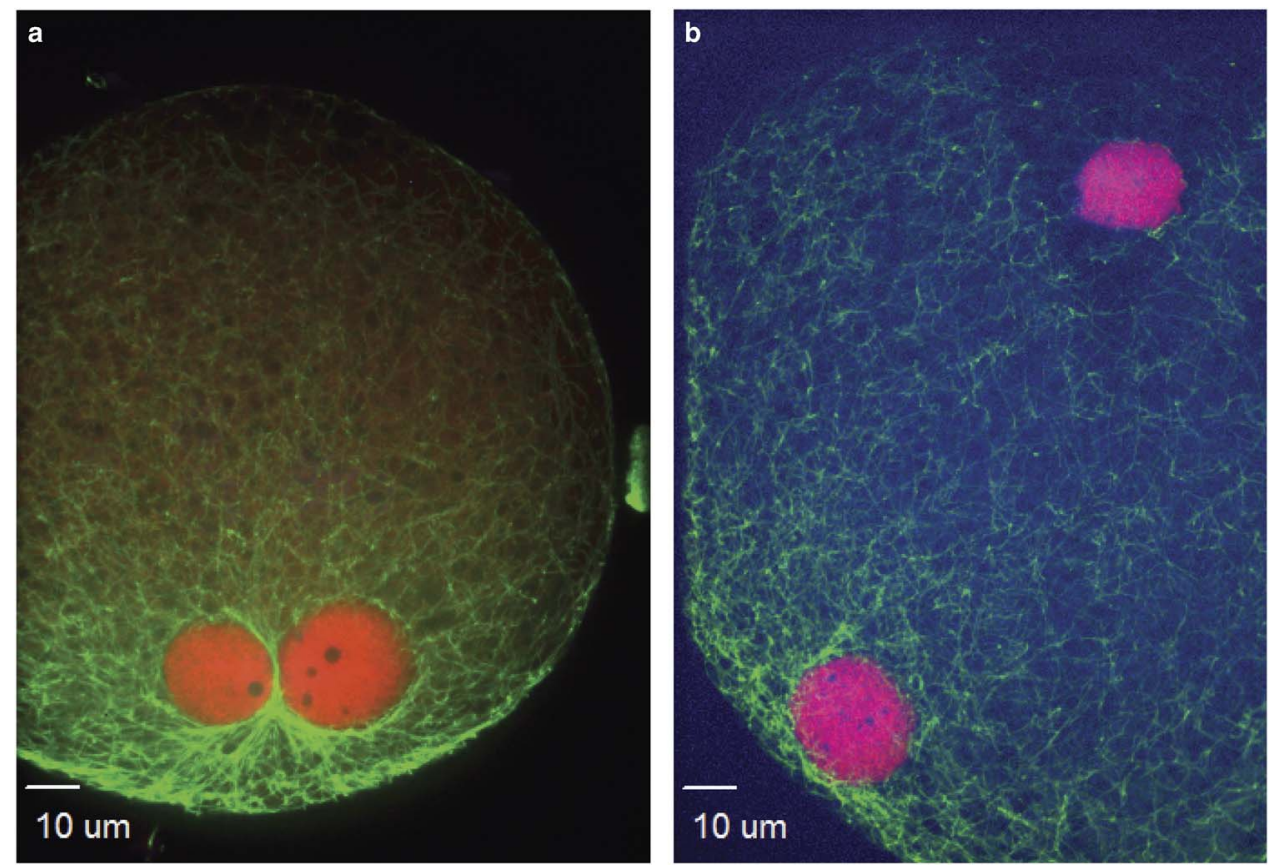

Figure 2. Nucleolus precursor bodies were observed within pronuclei at apposed (a) or distant (b) locations (red, centromere; green, tubulin). 
Tremoleda et al., 2003). Our first observations were done $4 \mathrm{~h}$ after ICSI, and in most presumptive zygotes, the maternal metaphase II spindle with aligned chromosomes, first polar
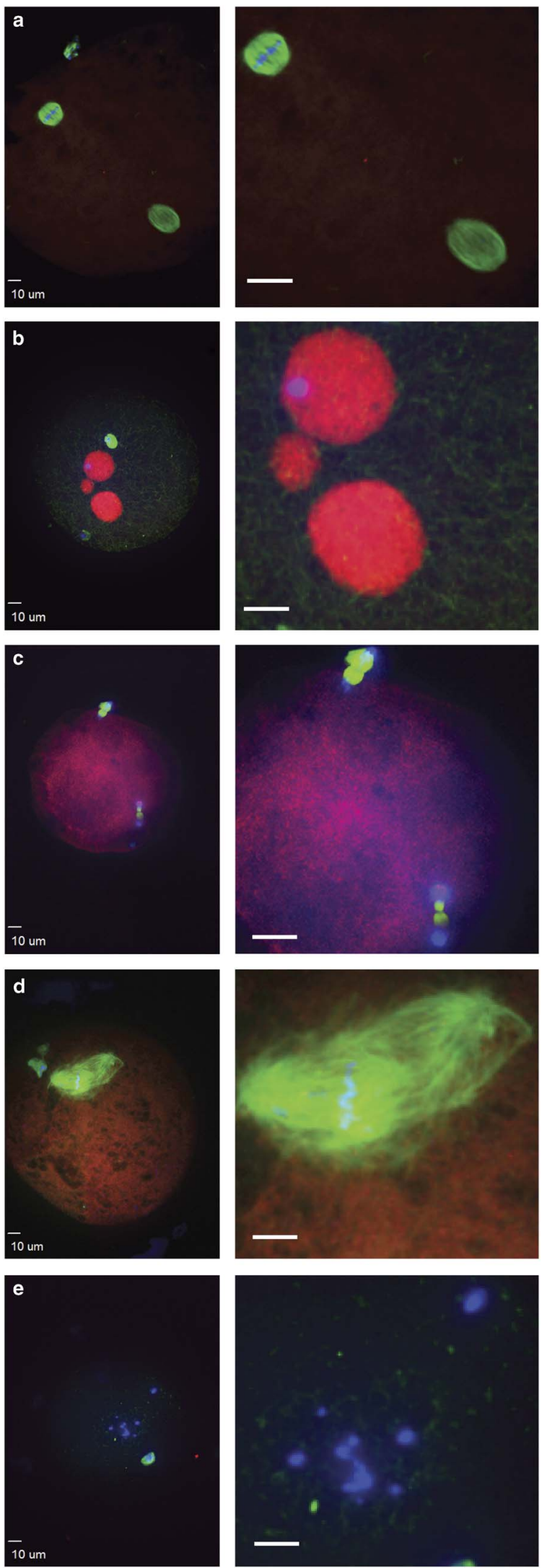

body, and sperm head were imaged. In the study by Tremoleda et al. (2003), oocytes remained at metaphase II directly after sperm injection, with signs of oocyte activation noted in most oocytes at $6 \mathrm{~h}$ and leading to the second meiotic division with extrusion of the second polar body. We observed the anaphase to telophase transition, prior to extrusion of a second polar body, by $4 \mathrm{~h}$ in approximately one quarter of injected oocytes.

In our study, IVO seemed to develop to pronuclei sooner after ICSI than IVM, with the highest percentages of pronuclei noted after ICSI at 6 and $8 \mathrm{~h}$ for IVO, in comparison with 12 and $16 \mathrm{~h}$ for IVM. Within pronuclei were distinct areas with no CREST anticentromere staining, signifying NPB (Fig. 2a). The timing of pronuclei formation agreed with previous reports using IVM oocytes, with half of sperm-injected oocytes reaching the pronuclear stage by $12 \mathrm{~h}$, while the remaining presumptive zygotes were still in earlier stages of development (Tremoleda et al., 2003). In another study, half of the sperm-injected IVM oocytes had two pronuclei at $20 \mathrm{~h}$ after ICSI, but none had two pronuclei at $10 \mathrm{~h}$ after ICSI (Tremoleda et al., 2003). A significant percentage $(36 \%)$ of these sperm-injected, IVM oocytes did not cleave into two cells until $48 \mathrm{~h}$ after ICSI (Tremoleda et al., 2003). In our laboratory, we would expect cleavage or indicators or impending cleavage for IVO and IVM oocytes by $24 \mathrm{~h}$ after ICSI (Carnevale, personal communication, 2017).

The timing of pronuclei formation for IVO and IVM could be impacted by many factors other than maturation method, including differences in sperm, procedures, inherent oocyte quality, and total time of maturation. However, oocyte quality and cytoplasmic maturation could also differ between IVO and IVM oocytes (Sutton et al., 2003; Gilchrist \& Thompson, 2007). Oocytes collected from all follicles from excised ovaries represent a heterogenous group of oocytes in different stages of competence, maturation, and atresia (Hinrichs, 1991). In contrast, oocytes collected from dominant, maturing follicles are in a relatively consistent stage of maturation, with ovulation of a metaphase II oocyte anticipated $\sim 38 \mathrm{~h}$ after administration of induction drugs (Figueiredo et al., 2011). In this study, IVO oocytes were collected during the process of maturation, probably at metaphase I, and cultured in medium for the completion of maturation, in a system that has been proven to result in developmentally competent oocytes (Carnevale et al., 2004). In contrast IVM oocytes were collected from follicles of various sizes and from ovaries of mares of unknown ages or stages of their reproductive cycle or pregnancy. Oocytes collected from small- or medium-sized,

Figure 3. Abnormal morphologies of potential equine zygotes after intracytoplasmic sperm injection include (a) premature chromosome condensation, with female spindle (top left) and male chromosomes flanked by a spindle structure (lower right); (b) multiple pronuclei; (c) sperm chromatin induced ectopic polar body, represented by the two sets of chromosomes undergoing anaphase; (d) multipolar spindle; (e) scattered maternal chromosomes (blue, DNA; red, centromeres and kinetochores; green, tubulin). 


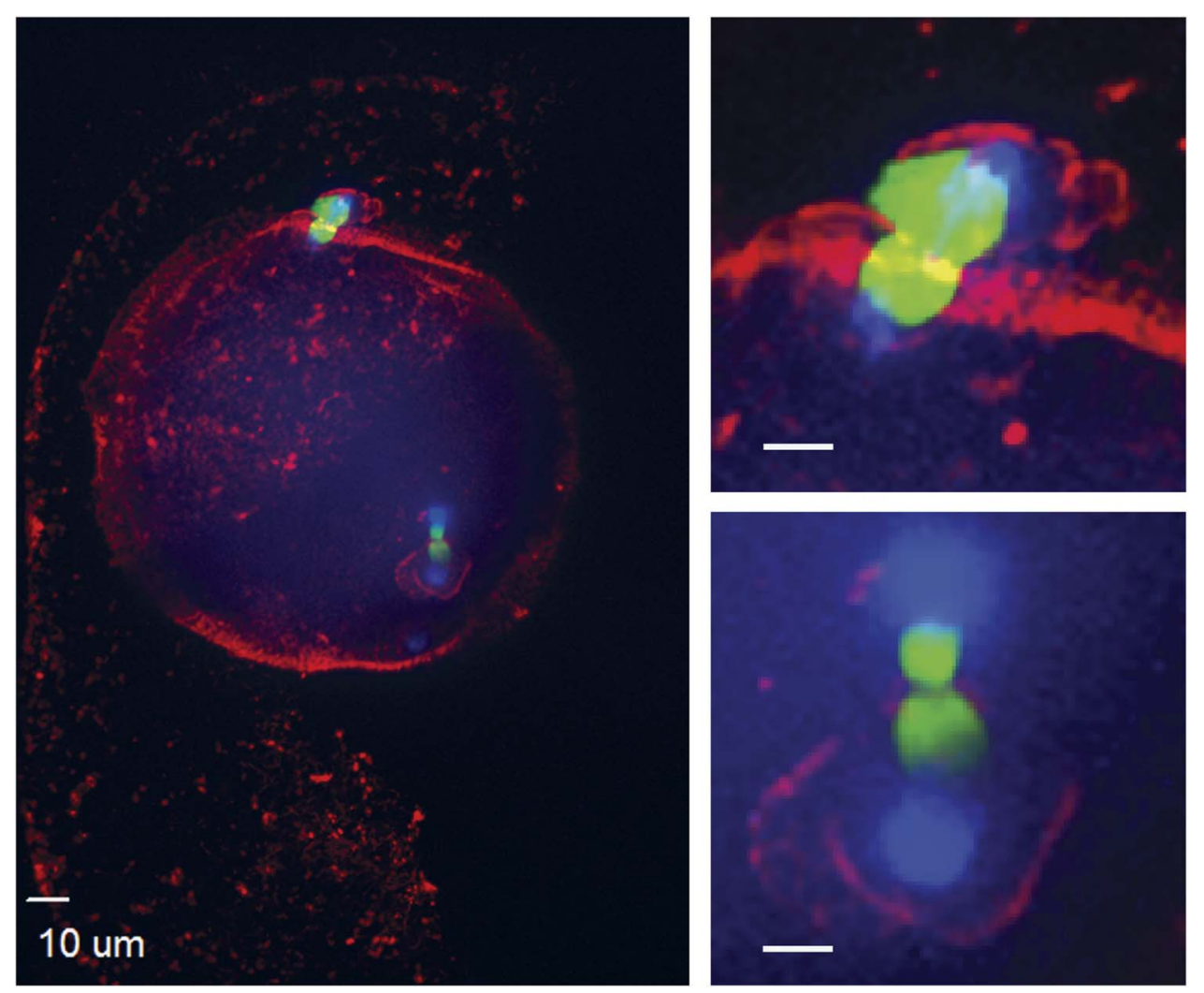

Figure 4. Actin cytoskeleton localization during ectopic polar body extrusion. In the left panel, cortical actin is concentrated around the two points of DNA extrusion. Top right and bottom right panels are magnified images of the two points of extrusion (blue, DNA; red, actin; green, tubulin).

immature follicles can be less developmentally competent, as they complete maturation in artificial conditions over a limited time, in contrast to natural conditions within the dominant follicle (Hyttel et al., 1997). In addition, synchronization of nuclear and cytoplasmic maturation can be impacted when oocytes are matured in vitro. Epigenetic

Table 2. Number of Potential Equine Zygotes with Abnormal Morphologies at 4, 6, 8, 12, and 16h After Intracytoplasmic Sperm Injection $(0 \mathrm{~h})$ Per Total Injected Oocytes Matured In Vivo (IVO) or In Vitro (IVM).

\begin{tabular}{|c|c|c|c|c|c|c|}
\hline Abnormality & $4 \mathrm{~h}$ & $6 \mathrm{~h}$ & $8 \mathrm{~h}$ & $12 \mathrm{~h}$ & $16 \mathrm{~h}$ & Total Zygotes \\
\hline \multicolumn{7}{|c|}{ Premature chromosome condensation } \\
\hline IVO & $0 / 5(0)$ & $0 / 6(0)$ & $0 / 5(0)$ & $0 / 5(0)$ & $0 / 7(0)$ & $0 / 28(0)$ \\
\hline IVM & $1 / 8(13)$ & $1 / 8(13)$ & $2 / 8(25)$ & $0 / 10(0)$ & $1 / 10(10)$ & $5 / 44(11)$ \\
\hline \multicolumn{7}{|c|}{ Multiple (>2) pronuclei } \\
\hline IVO & $0 / 5(0)$ & $0 / 6(0)$ & $0 / 5(0)$ & $0 / 5(0)$ & $0 / 7(0)$ & $0 / 28(0)$ \\
\hline IVM & $1 / 8(13)$ & $0 / 8(0)$ & $0 / 8(0)$ & $0 / 10(0)$ & $0 / 10(0)$ & $1 / 44(3)$ \\
\hline \multicolumn{7}{|c|}{ Sperm chromatin induced ectopic polar body } \\
\hline IVO & $0 / 5(0)$ & $0 / 6(0)$ & $0 / 5(0)$ & $0 / 5(0)$ & $0 / 7(0)$ & $0 / 28(0)$ \\
\hline IVM & $0 / 8(0)$ & $1 / 8(13)$ & $3 / 8(30)$ & $0 / 10(0)$ & $0 / 10(0)$ & $4 / 44(9)$ \\
\hline \multicolumn{7}{|c|}{ Multipolar spindle } \\
\hline IVO & $0 / 5(0)$ & $0 / 6(0)$ & $0 / 5(0)$ & $1 / 5(20)$ & $0 / 7(0)$ & $1 / 28(4)$ \\
\hline IVM & $0 / 8(0)$ & $0 / 8(0)$ & $0 / 8(0)$ & $0 / 10(0)$ & $1 / 10(10)$ & $1 / 44(2)$ \\
\hline \multicolumn{7}{|c|}{ Scattered chromosomes and sperm head intact } \\
\hline IVO & $0 / 5(0)$ & $0 / 6(0)$ & $0 / 5(0)$ & $0 / 5(0)$ & $2 / 7(29)$ & $2 / 28(7)$ \\
\hline IVM & $0 / 8(0)$ & $0 / 8(0)$ & $0 / 8(0)$ & $1 / 10(10)$ & $1 / 10(10)$ & $2 / 44(5)$ \\
\hline \multicolumn{7}{|c|}{ Total abnormalities } \\
\hline IVO & $0 / 5(0)$ & $0 / 6(0)$ & $0 / 5(0)$ & $1 / 5(20)$ & $2 / 7(29)$ & $3 / 28^{a}(11)$ \\
\hline IVM & $2 / 8(25)$ & $2 / 8(25)$ & $5 / 8(63)$ & $1 / 10(10)$ & $3 / 10(30)$ & $13 / 44^{\mathrm{b}}(30)$ \\
\hline
\end{tabular}

The total number of zygotes with morphologic abnormalities was higher $(p=0.04)$ for IVM when compared with IVO (as denoted by bold numbers and different superscripts). 
modifications occur in gametes and in early embryos (Reik et al., 2001; Bromfield et al., 2007; Cantone \& Fisher, 2013), and ART procedures and in vitro culture could cause epigenetic disturbances that affect oocyte competence, pregnancy, and offspring health (Bromfield et al., 2007; El Hajj \& Haaf, 2013). In our study, no definitive differences in zygote development were noted with the limited numbers of IVO and IVM oocytes, although zygotes from IVM subjectively appeared to develop slower. However, oocyte maturation groups differed in that significantly more zygotes from IVM, than IVO, had abnormalities suggestive of developmental failure. One potential risk of maturation in vitro is that nuclear and cytoplasmic maturation are not synchronized and can result in collateral effects on embryonic development (Smitz et al., 2011; Sanfins et al., 2015). Transcriptional profiling after in vitro maturation of oocytes from cattle, women and mice has confirmed changes in genes and pathways, which could affect postfertilization events (Rinaudo \& Schultz, 2004; Mamo et al., 2011; El Hajj \& Haaf, 2013). The extent that maturation in vitro affected oocyte quality in this study could not be directly determined, primarily because of the inherent variability within the population of immature oocytes.

After sperm injection, factors associated with the sperm and oocyte are critical for oocyte activation, decondensation of the sperm chromatin, and initiation of embryo development (Choi et al., 2004; Galli et al., 2007). Alterations in these processes can result in abnormal development, and abnormal morphologies were observed in some potential zygotes. Sperm-transmitted DNA damage leads to diverse abnormal reproductive outcomes and paternal genome loss, and it can be caused by different sperm chromatin defects, including premature sperm condensation and ectopic polar body extrusion after ICSI (Schmiady et al., 1996; Marchetti \& Wyrobek, 2005; Deng \& Li, 2009; Marchetti et al., 2015). After aneuploidy, the most common cause of fertilization failure in human in vitro fertilization and ICSI is premature sperm condensation (Edirisinghe et al., 1997; Moghbelinejad et al., 2013). Proper meiotic resumption of the oocyte is required to avoid premature condensation of the sperm head, which leads to DNA damage and aneuploidy in human oocytes (Manandhar \& Toshimori, 2003). In our study, premature sperm condensation was observed only in IVM, as previously reported (Tremoleda et al., 2003). Another sperm-related abnormality, specific to IVM in our study, was sperm chromatin induced ectopic polar body extrusion, with a spindle forming around sperm chromatin and leading to failure of normal zygote development because of the loss of paternal chromatin (Deng \& Li, 2009). Premature sperm chromatin condensation and sperm chromatin induced ectopic polar bodies were only observed in IVM, suggesting that progression to the pronuclei stage was disrupted during oocyte activation in IVM oocytes or alterations of sperm DNA specific packaging and protamine deficiency (Schmiady et al., 1996; Deng \& Li, 2009). However, we cannot exclude the potential that intrinsic oocyte quality or the stallion affected these results, as these variables were different for the two ICSI systems. Additionally, the two post insemination culture conditions differed between laboratories where the experiments were performed. Both DMEM/ F12 and SOF media are used clinically with high success rates, but we acknowledge that diverse culture media, and therefore the environment during embryo development, could have affected the results observed in this study.

Additional zygote abnormalities included multiple pronuclei and multipolar spindle or presence of scattered maternal chromosomes and intact sperm head (chromosome fragmentation). Multipolar spindles suggest failure in spindle assembly checkpoints, and they were observed in a single oocyte from IVO and IVM (Sluder et al., 1997; Courtois et al., 2012). Scattered chromosomes and a sperm head were also observed in two potential zygotes from IVO and two from IVM. Multiple pronuclei suggest the failure of extrusion of the second polar body, possibly due to poor oocyte quality or sperm chromatin defects (Rosenbusch, 2001). Overall, we observed more morphological abnormalities in zygotes from IVM than IVO. This could have been caused by alterations in normal oocyte maturation in vitro; however, the increased diversity of oocytes collected from equine ovaries is also likely to affect developmental potential.

Although the clinical use and success of ICSI has dramatically increased in the equine industry over the last decade, this is one of few studies that has focused on factors that impact zygote development. The lack of ongoing research is primarily due to our lack of knowledge regarding normal equine zygote formation and the expense and difficulty in obtaining equine oocytes, making projects that require large numbers of oocytes impractical and overly expensive. Often, the end points of projects studying equine ICSI are cleavage and blastocyst rates. Although these end points are important, they do not assess if fertilization was normal or why fertilization failure might have occurred. Therefore, more research is needed in this area to increase our understanding of equine fertilization and embryo development and to optimize success of ICSI. In this study, we demonstrated that confocal microscopy could provide meaningful data when using relatively low numbers of sperm-injected oocytes. Although multiple factors were different in regard to IVO or IVM, the results demonstrated some of the benefits and drawbacks for oocyte collection and maturation methods that are currently being used for clinical and research ICSI programs. The timelines provided by this research will allow future investigators to pick optimal time point(s) for observations of equine zygotes after ICSI of IVO or IVM. This information can be used for future investigations, especially as related to sperm and oocyte quality. The research demonstrates that confocal microscopy of individual zygotes can be a powerful tool in assessing factors impacting fertilization and zygote development in the horse, and it provides methodology that can be used by researchers to practically investigate treatment effects.

\section{CONCLUSIONS}

In conclusion, we used confocal microscopy to observe equine zygotes at timed intervals after ICSI of IVO or IVM. 
A similar progression of events during zygote development occurred in both groups. IVO when compared with IVM appeared to have a more rapid progression to pronuclei, although some of the potential zygotes were delayed or arrested in development. Abnormal zygote morphologies occurred more frequently in IVM than IVO. Confocal microscopy provided a feasible method to assess zygote development after in vivo or in vitro oocyte maturation using a limited number of samples.

\section{ACKNOWLEDGMENTS}

Mare management, oocyte collection, and sample processing was done with the help of staff and students in the Assisted Reproduction Program at the Equine Reproduction Laboratory, Colorado State University (IVO), and ICSI was performed by JoAnne Stokes. The Cecil and Irene Hylton Foundation funded the study. Franc Stone and Abney Foundation scholarships and the Assisted Reproduction Program provided graduate support. Supplemental support came from a core infrastructure grant for microscope imaging and R01GM088371 (JGD) at Colorado State University and Ex Ovo Omnia project from Regione Sardegna and Lombardia at Avantea, Laboratory of Reproductive Technologies, Cremona, Italy (C.G.). The supply of ovaries was possible thanks to the collaboration of the Zerbini and Ragazzi slaughterhouse. The help of the technical staff at Avantea is also acknowledged.

\section{REFERENCES}

Altermatt, J.L., Suh, T.K., Stokes, J.E. \& Carnevale, E.M. (2009). Effects of age and equine follicle-stimulating hormone (eFSH) on collection and viability of equine oocytes assessed by morphology and developmental competency after intracytoplasmic sperm injection (ICSI). Reprod Fertil Dev 21(4), 615-623.

Ambruosi, B., Lacalandra, G.M., Iorga, A.I., De Santis, T., Mugnier, S., Matarrese, R., Goudet, G. \& Dell'aquila, M.E. (2009). Cytoplasmic lipid droplets and mitochondrial distribution in equine oocytes: Implications on oocyte maturation, fertilization and developmental competence after ICSI. Theriogenology 71(7), 1093-1104.

Arlotto, T., Schwartz, J.L., First, N.L. \& Leibfried-Rutledge, M.L. (1996). Aspects of follicle and oocyte stage that affect in vitro maturation and development of bovine oocytes. Theriogenology 45(5), 943-956.

BarretT, S.L. \& Albertini, D.F. (2007). Allocation of gamma-tubulin between oocyte cortex and meiotic spindle influences asymmetric cytokinesis in the mouse oocyte. Biol Reprod 76(6), 949-957.

Bromfield, J., Messamore, W. \& Albertini, D.F. (2007). Epigenetic regulation during mammalian oogenesis. Reprod Fertil Dev 20(1), 74-80.

Cantone, I. \& Fisher, A.G. (2013). Epigenetic programming and reprogramming during development. Nat Struct Mol Biol 20(3), 282-289.

Carnevale, E.M. (2016). Advances in collection, transport and maturation of equine oocytes for assisted reproductive techniques. Vet Clin North Am Equine Pract 32(3), 379-399.
Carnevale, E. \& Ginther, O. (1995). Defective oocytes as a cause of subfertility in old mares. Biol Reprod Monogr 1, 209-214.

Carnevale, E.M., da Silva, M.A.C., Maclellan, L.J., Seidel, G.E. \& SQUiRES, E.L. (2004). Use of parentage testing to determine optimum insemination time and culture media for oocyte transfer in mares. Reproduction 128(5), 623-628.

Carnevale, E.M., Maclellan, L.J., Coutinho da Silva, M.A., SCOTT, T.J. \& SQUiRES, E.L. (2000). Comparison of culture and insemination techniques for equine oocyte transfer. Theriogenology 54(6), 981-987.

Carnevale, E.M. \& Sessions, D.R. (2012). In vitro production of equine embryos. J Equine Vet Sci 32(7), 367-371.

Carnevale, E.M., Stokes, J., Squires, E.L., Campos-Chillon, L.F., Altermatt, J. \& Suh, T.K. (2007). Clinical use of intracytoplasmic sperm injection in horses. Proc Am Assoc Equine Pract 53, 560.

Choi, Y.H., Love, L.B., Varner, D.D. \& Hinrichs, K. (2004). Factors affecting developmental competence of equine oocytes after intracytoplasmic sperm injection. Reproduction 127(2), 187-194.

Colleoni, S., Barbacini, S., Necchi, D., Duchi, R., Lazzari, G. \& GALLI, C. (2007). Application of ovum pick-up, intracytoplasmic sperm injection and embryo culture in equine practice. Amer Assoc Equine Practitioners Proc 53, 554-559.

Colleoni, S., Lagutina, I., Lazzari, G., Rodriguez-Martinez, H., Galli, C. \& Morrell, J.M. (2011). New methods for selecting stallion spermatozoa for assisted reproduction. J Equine Vet Sci 31(9), 536-541.

Courtois, A., Schuh, M., Ellenberg, J. \& Hirragi, T. (2012). The transition from meiotic to mitotic spindle assembly is gradual during early mammalian development. J Cell Biol 198(3), 357-370.

Deng, M. \& LI, R. (2009). Sperm chromatin-induced ectopic polar body extrusion in mouse eggs after ICSI and delayed egg activation. PLoS One 4(9), e7171.

Edirisinghe, W.R., Murch, A., Junk, S. \& Yovich, J.L. (1997). Cytogenetic abnormalities of unfertilized oocytes generated from in-vitro fertilization and intracytoplasmic sperm injection: a double-blind study. Hum Reprod 12(12), 2784-2791.

EDwARDS, R.G. (1965). Maturation in vitro of mouse, sheep, cow, pig, rhesus monkey and human ovarian oocytes. Nature 208(5008), 349-351.

El HaJJ, N. \& HaAf, T. (2013). Epigenetic disturbances in in vitro cultured gametes and embryos: implications for human assisted reproduction. Fertil Steril 99(3), 632-641.

Enders, A.C., Liu, I.K., Bowers, J., Lantz, K.C., Schlafke, S. \& SuAREZ, S. (1987). The ovulated ovum of the horse: cytology of nonfertilized ova to pronuclear stage ova. Biol Reprod 37(2), 453-466.

Figueiredo, T., Paiva, R., Kozicki, L.E., Kaercher, F., Weiss, R.R., SANTOS, I.W.d. \& Muradas, P.R. (2011). Induction of ovulation in quarter horse mares through the use of deslorelin acetate and human chorionic gonadotrophin (hCG). Braz Arch Biol Technol 54(3), 517-521.

Freeman, D.A., Weber, J.A., Geary, R.T. \& Woods, G.L. (1991). Time of embryo transport through the mare oviduct. Theriogenology 36(5), 823-830.

Galli, C., Colleoni, S., Duchi, R., Lagutina, I. \& Lazzari, G. (2007). Developmental competence of equine oocytes and embryos obtained by in vitro procedures ranging from in vitro maturation and ICSI to embryo culture, cryopreservation and somatic cell nuclear transfer. Anim Reprod Sci 98(1-2), 39-55. 
Galli, C., Colleoni, S., Duchi, R., Lagutina, I. \& LazZari, G. (2013). Equine assisted reproduction and embryo technologies. Anim Reprod 10, 334-343.

Galli, C., Duchi, R., Colleoni, S., Lagutina, I. \& Lazzari, G. (2014). Ovum pick up, intracytoplasmic sperm injection and somatic cell nuclear transfer in cattle, buffalo and horses: From the research laboratory to clinical practice. Theriogenology 81(1), 138-151.

Gilchrist, R.B. \& Thompson, J.G. (2007). Oocyte maturation: Emerging concepts and technologies to improve developmental potential in vitro. Theriogenology 67(1), 6-15.

Grondahl, C., Hansen, T.H., Hossaini, A., Heinze, I., Greve, T. \& Hyttel, P. (1997). Intracytoplasmic sperm injection of in vitromatured equine oocytes. Biol Reprod 57(6), 1495-1501.

Grondahl, C. \& HytTel, P. (1996). Nucleologenesis and ribonucleic acid synthesis in preimplantation equine embryos. Biol Reprod 55(4), 769-774.

Hinrichs, K. (1991). The relationship of follicle atresia to follicle size, oocyte recovery rate on aspiration, and oocyte morphology in the mare. Theriogenology 36(2), 157-168.

Hinrichs, K. (2013). Assisted reproduction techniques in the horse Reprod Fertil Dev 25(1), 80-93.

Hinrichs, K., Schmidt, A.L., Friedman, P.P., Selgrath, J.P. \& Martin, M.G. (1993). In vitro maturation of horse oocytes: Characterization of chromatin configuration using fluorescence microscopy. Biol Reprod 48(2), 363-370.

Hyttel, P., Fair, T., Callesen, H. \& Greve, T. (1997). Oocyte growth, capacitation and final maturation in cattle. Theriogenology 47(1), 23-32.

Lazzari, G., Wrenzycki, C., Herrmann, D., Duchi, R., Kruip, T., Niemann, H. \& Galdi, C. (2002). Cellular and molecular deviations in bovine in vitro-produced embryos are related to the large offspring syndrome. Biol Reprod 67(3), 767-775.

Leemans, B., Gadella, B.M., Stout, T.A., De Schauwer, C., Nelis, H., Hoogewis, M. \& VAN Soom, A. (2016). Why doesn't conventional IVF work in the horse? The equine oviduct as a microenvironment for capacitation/fertilization. Reproduction 152(6), R233-R245.

Lonergan, P. \& Fair, T. (2016). Maturation of oocytes in vitro. Annu Rev Anim Biosci 4, 255-268.

Mamo, S., Carter, F., Lonergan, P., Leal, C.L., Al Naib, A., McGettigan, P., Mehta, J.P., Evans, A.C. \& Fair, T. (2011). Sequential analysis of global gene expression profiles in immature and in vitro matured bovine oocytes: Potential molecular markers of oocyte maturation. BMC Genom 12, 151.

Manandhar, G. \& Toshimori, K. (2003). Fate of postacrosomal perinuclear theca recognized by monoclonal antibody MN13 after sperm head microinjection and its role in oocyte activation in mice. Biol Reprod 68(2), 655-663.
Marchetti, F., Bishop, J., Gingerich, J. \& Wyrobek, A.J. (2015). Meiotic interstrand DNA damage escapes paternal repair and causes chromosomal aberrations in the zygote by maternal misrepair. Sci Rep 5, 7689.

Marchetti, F. \& WyrobeK, A.J. (2005). Mechanisms and consequences of paternally-transmitted chromosomal abnormalities. Birth Defects Res C Embryo Today 75(2), 112-129.

Messinger, S.M. \& Albertini, D.F. (1991). Centrosome and microtubule dynamics during meiotic progression in the mouse oocyte. J Cell Sci 100(Pt 2), 289-298.

Moghbelinejad, S., Mozdarani, H. \& Rezaeian, Z. (2013). The rates of premature chromosome condensation and embryo development after injection of irradiated sperms into hamster oocytes. Iran J Reprod Med 11(5), 391-398.

Reik, W., Dean, W. \& Walter, J. (2001). Epigenetic reprogramming in mammalian development. Science 293(5532), 1089-1093.

Rinaudo, P. \& Schultz, R.M. (2004). Effects of embryo culture on global pattern of gene expression in preimplantation mouse embryos. Reproduction 128(3), 301-311.

Rosenbusch, B. (2001). Digynic triploidy: Possible mechanisms. Prenat Diagn 21(3), 234.

Sanfins, A., Plancha, C.E. \& Albertini, D.F. (2015). Preimplantation developmental potential from in vivo and in vitro matured mouse oocytes: A cytoskeletal perspective on oocyte quality. J Assist Reprod Genet 32(1), 127-136.

Schmiady, H., Tandler-Schneider, A. \& Kentenich, H. (1996). Premature chromosome condensation of the sperm nucleus after intracytoplasmic sperm injection. Hum Reprod 11(10), 2239-2245.

Sluder, G., Thompson, E.A., Miller, F.J., Hayes, J. \& Rieder, C.L. (1997). The checkpoint control for anaphase onset does not monitor excess numbers of spindle poles or bipolar spindle symmetry. J Cell Sci 110(Pt 4), 421-429.

Smitz, J.E., Thompson, J.G. \& Gilchrist, R.B. (2011). The promise of in vitro maturation in assisted reproduction and fertility preservation. Semin Reprod Med 29(1), 24-37.

Squires, E., Carnevale, E., McCue, P. \& Bruemmer, J. (2003). Embryo technologies in the horse. Theriogenology 59(1), $151-170$

Sutton, M.L., Gilchrist, R.B. \& Thompson, J.G. (2003). Effects of in-vivo and in-vitro environments on the metabolism of the cumulus-oocyte complex and its influence on oocyte developmental capacity. Hum Reprod Update 9(1), 35-48.

Tremoleda, J.L., Van Haeften, T., Stout, T.A., Colenbrander, B. \& BeVERs, M.M. (2003). Cytoskeleton and chromatin reorganization in horse oocytes following intracytoplasmic sperm injection: Patterns associated with normal and defective fertilization. Biol Reprod 69(1), 186-194. 